\title{
Bromsulphthalein metabolism in acute alcoholic liver disease
}

\author{
PATRICIA WILKINSON, D. M. O'DAY, K. J. BREEN, \\ AND J. G. RANKIN \\ From the University of Melbourne Department of Medicine, \\ St Vincent's Hospital, Melbourne, Australia
}

Routine biochemical tests of hepatic function are useful in detecting subclinical acute alcoholic liver disease, but they do not correlate well with abnormalities of hepatic histology, and they are too nonspecific to use in unravelling the pathophysiology of the condition. The most frequently observed biochemical abnormalities are raised levels of serum glutamic oxaloacetic transaminase (SGOT), serum alkaline phosphatase (SAP), and bromsulphthalein (BSP) retention, suggesting either parenchymal cell injury (Leevy, 1962; Green, Mistilis, and Schiff, 1963), abnormal canalicular function (Ballard, Bernstein, and Farrar, 1961; Sataline and Matre, 1963), or both. The histological changes observed in patients with acute alcoholic liver disease vary greatly. In a minority of patients the liver appears normal under light microscopy, whilst in the majority there is either fatty infiltration alone, or acute alcoholic hepatitis in which parenchymal cell necrosis and inflammation accompany the fatty change. Such histological changes, however, are not always associated with abnormal physical signs or altered liver function tests, and conversely clinical and biochemical evidence of liver damage may coexist with a liver biopsy which appears normal under the light microscope (Leevy, 1962; Green, 1965).

Just as the electron microscope has been used to reveal the early structural changes of acute liver disease not apparent on light microscopy, so might more refined biochemical methods be used to study specific alterations in hepatic function. In this way it might ultimately be possible to learn not only about the nature and consequences of acute alcoholic liver injury but also about normal metabolic pathways. In the present investigation BSP metabolism has been studied in patients suffering from acute alcoholic liver disease and the results obtained have been correlated with other clinical, laboratory, and histological data. Bromsulphthalein follows a metabolic pathway involving uptake by the liver, conjugation and biliary excretion, and abnormalities of the BSP retention test are the most sensitive routine index of early alcoholic liver disease (Leevy, 1962; Green, 1965). Unfortunately, this test does not differentiate between parenchymal injury and biliary obstruction. However, a clinical technique is available (Wheeler, Meltzer, and Bradley, 1960) which makes it possible to measure independently in man the storage $\left(\mathbf{S}_{\mathrm{BSP}}\right)$ of the dye by the liver and its maximum rate of excretion (TmBSP). This method of investigating BSP metabolism has been used in the study reported here. The values obtained for $S_{\mathrm{BSP}}$ and TmBSP have been examined in relation to details of clinical assessment, routine liver function tests, and liver biopsy histology, and the results and their interpretation are the subject of the remainder of the present paper.

\section{PATIENTS AND METHODS}

Two groups of men were investigated. In the first group were 27 patients who were referred to the University of Melbourne Department of Medicine Alcoholism Clinic for treatment of chronic alcoholism, their ages ranging from 27 to 59 years (mean $46 \cdot 1$ years). All were admitted to hospital as inpatients where they received a normal diet with oral or intramuscular vitamin B supplements. Thirteen also received chlordiazepoxide ${ }^{1}$ to suppress or prevent withdrawal symptoms. No other tranquillizers or sedatives were given. In the second group were three convalescent patients, aged 24,42 , and 47 years, who had neither a history of alcoholism nor evidence of hepatobiliary or cardiac disease.

In each alcoholic patient liver biopsy, routine liver function tests, and measurements of $S_{B S P}$ and TmBSP were performed within a period of 48 hours. These initial investigations were carried out between two and 19 days after the cessation of drinking. In six of these alcoholic patients measurement of $S_{\text {BSP }}$ and TmBSP were carried out a second time. In one patient this was 21 months later, after a second bout of heavy drinking, the patient being abstinent in between. In the other five patients the second series of investigations was made

'Librium (Roche Products Pty Ltd). 
after periods of abstinence ranging from nine to 150 days.

MEASUREMENT OF SBSP AND TmBSP The hepatic storage capacity $\left(\mathrm{S}_{\mathrm{BSP}}\right)$ and biliary transport maximum $\left(\mathrm{Tm}_{\mathrm{BSP}}\right)$ for BSP were measured using the two-phase constant infusion technique of Wheeler et al (1960).

All patients were examined following an overnight fast. Using a Harvard peristaltic constant infusion pump, a solution of BSP in normal saline was infused into an antecubital vein at a rate which was adjusted during the first phase to give a rising plasma concentration of the dye. After 30 minutes' equilibration a series of five venous or arterial samples was obtained from the opposite arm at five-minute intervals. Then, for the second phase, the infusion was slowed to about one third of the initial rate and after another 30 minute equilibration period, a further series of samples was obtained at five-minute intervals. At the end of the infusion the plasma volume was measured, using ${ }^{131}$ I-labelled human serum albumin. The BSP concentrations in the plasma samples were estimated by the method of Seligson, Marino, and Dodson (1957).

Values for $\mathrm{S}_{\mathrm{BSP}}$ and $\mathrm{Tm}_{\mathrm{BSP}} \mathrm{were}$ then derived by solving the equation $I=T m+P(P V+S)$ for the two phases of BSP infusion. I (infusion rate) was measured in milligrams per minute, $\mathbf{P}$ (rate of change of plasma concentration of dye in milligrams per $100 \mathrm{ml}$ per minute) was calculated mathematically from the plasma concentrations of dye during the first and second phases of infusion, and PV (plasma volume) was expressed in $100 \mathrm{ml}$ of plasma. The value for $\mathrm{S}_{\mathrm{BSP}}$ was expressed as milligrams of dye stored per milligram per $100 \mathrm{ml}$ of plasma concentration and TmBSP was measured in milligrams per minute.

\section{RESULTS}

DRINKING HABITS OF ALCOHOLIC PATIENTS Nine of the alcoholic patients studied were 'spree' drinkers who alternated periods of excessive drinking with intervals of relative or complete abstinence. The remainder had drunk heavily and consistently for several years until the time of admission. The estimated intake of alcohol in these 27 patients ranged between 120 and $400 \mathrm{~g}$ per day (mean $250 \mathrm{~g}$ per day). The type of alcoholic beverage varied greatly. Seventeen men drank various conbinations of beer, wine, spirits, and methylated spirits. The remaining 10 favoured one beverage only; in nine this was beer, in the tenth whisky.

CLINICAL AND LABORATORY FINDINGS IN ALCOHOLIC PATIENTS A palpable, tender liver was detectable in 16 patients. Eight patients had reversible peripheral neuropathy, none had clinical evidence of cardiac disease.

No patient was clinically jaundiced when studied, the highest serum bilirubin value being $1.6 \mathrm{mg}$ per $100 \mathrm{ml}$; SGOT and SAP estimations were either normal or showed modest rises, the highest SGOT being 95 Sigma-Frankel units per $\mathrm{ml}$ and the highest SAP 16 King-Armstrong units per $100 \mathrm{ml}$.

Six patients had histologically normal liver biopsies; six had fatty infiltration without cell necrosis; six had acute alcoholic hepatitis, that is, parenchymal cell necrosis and inflammatory response as well as fatty change; and three had patchy cell necrosis without fatty infiltration. Four of the 12 patients with acute alcoholic hepatitis also had minor degrees of portal tract fibrosis. No patient had histological evidence of cirrhosis.

VALUES FOR SBSP AND TmBSP The results obtained for $S_{\mathrm{BSP}}$ and $\mathrm{Tm}_{\mathrm{BSP}}$ in the three non-alcoholic patients agreed well with the mean values reported by Preisig, Williams, Sweeting, and Bradley (1966) for normal male volunteers (Table I).

The initial studies carried out in the 27 alcoholic patients revealed a reduction of $S_{B S P}$ in $15, T m_{B S P}$ remaining normal in all subjects. This defect in $\mathbf{S}_{\mathrm{BSP}}$ could not be correlated with age, drinking habits, SGOT or SAP elevations, or histological changes seen in the liver biopsies. It did not coincide with either the presence of peripheral neuropathy or medication with chlordiazepoxide. In Table II, the results have been tabulated according to the histological findings and arranged in order of the severity of reduction in $\mathrm{S}_{\mathrm{BSP}}$.

The storage defect was most severe in those patients who had drunk most recently. Thirteen out of the 15 patients who were studied within a week of alcohol withdrawal had abnormal $S_{\text {BSP }}$ values, while all but two of the 12 patients studied during

TABLE I

BROMSULPHTHALEIN METABOLISM IN NON-ALCOHOLIC MEN WITHOUT LIVER DISEASE

\begin{tabular}{|c|c|c|c|c|c|}
\hline Patient & $\begin{array}{l}\text { Age } \\
\text { (yr) }\end{array}$ & $\begin{array}{l}\text { Weight } \\
\text { (kg) }\end{array}$ & Diagnosis & $\begin{array}{l}S_{B S P} \\
(\mathrm{mg} \text { per } \mathrm{mg} \\
\text { per } 100 \mathrm{ml} \text { ) }\end{array}$ & $\begin{array}{l}T m_{B S P} \\
\text { (mg per min) }\end{array}$ \\
\hline $\begin{array}{l}\mathbf{A} \\
\mathbf{B} \\
\mathbf{C}\end{array}$ & $\begin{array}{l}24 \\
42 \\
47\end{array}$ & $\begin{array}{l}71 \cdot 7 \\
88 \cdot 0 \\
66 \cdot 2\end{array}$ & $\begin{array}{l}\text { Peptic ulcer } \\
\text { Peptic ulcer } \\
\text { Anxiety state }\end{array}$ & $\begin{array}{l}77 \\
58 \\
60\end{array}$ & $\begin{array}{l}11 \cdot 1 \\
10 \cdot 0 \\
10 \cdot 6\end{array}$ \\
\hline \multicolumn{4}{|c|}{ Values for 18 normal men (Preisig et al, 1966) } & $6.9 \pm 17$ & $9 \cdot 6 \pm 19$ \\
\hline
\end{tabular}

Values for 18 normal men (Preisig et al, 1966)

$6 \cdot 9 \pm 17 \quad 9 \cdot 6 \pm 19$ 
TABLE II

BROMSULPHTHALEIN METABOLISM IN 27 ALCOHOLIC MEN RELATED TO HEPATIC HISTOLOGY

\begin{tabular}{|c|c|c|c|c|c|c|}
\hline Liver Biopsy & Patient No. & Age (yr) & Weight $(k g)$ & $\begin{array}{l}\text { Time Abstinent } \\
\text { before Test } \\
\text { (days) }\end{array}$ & $\begin{array}{l}S_{B S P} \\
(\mathrm{mg} \text { per } \mathrm{mg} \\
\text { per } 100 \mathrm{ml})\end{array}$ & $\begin{array}{l}\text { TmisP } \\
(\text { mg per min) }\end{array}$ \\
\hline Normal & $\begin{array}{r}2 \\
8 \\
15 \\
17 \\
22 \\
25\end{array}$ & $\begin{array}{l}42 \\
57 \\
33 \\
56 \\
42 \\
47\end{array}$ & $\begin{array}{l}60.4 \\
68.0 \\
62.5 \\
56.2 \\
58.6 \\
72.8\end{array}$ & $\begin{array}{r}6 \\
8 \\
7 \\
14 \\
11 \\
9\end{array}$ & $\begin{array}{l}11 \\
19 \\
34 \\
42 \\
49 \\
54\end{array}$ & $\begin{array}{r}9.3 \\
13.2 \\
6.3 \\
15 \cdot 1 \\
7 \cdot 8 \\
12.6\end{array}$ \\
\hline Fatty liver & $\begin{array}{r}4 \\
11 \\
16 \\
19 \\
20 \\
27\end{array}$ & $\begin{array}{l}57 \\
43 \\
32 \\
37 \\
35 \\
55\end{array}$ & $\begin{array}{l}63.4 \\
72.6 \\
62.2 \\
60.5 \\
61.9 \\
77.0\end{array}$ & $\begin{array}{r}3 \\
2 \\
4 \\
11 \\
8 \\
9\end{array}$ & $\begin{array}{l}14 \\
24 \\
41 \\
44 \\
46 \\
67\end{array}$ & $\begin{array}{r}9.6 \\
13.8 \\
10.3 \\
13.6 \\
12.9 \\
11.8\end{array}$ \\
\hline $\begin{array}{l}\text { Acute alcoholic } \\
\text { hepatitis }\end{array}$ & $\begin{array}{c}1 \\
3 \\
5^{1} \\
6 \\
7^{1} \\
9^{1} \\
10 a \\
\text { b } \\
12 \\
13 \\
18^{1} \\
24 \\
26\end{array}$ & $\begin{array}{l}46 \\
49 \\
45 \\
45 \\
53 \\
52 \\
42 \\
43 \\
31 \\
57 \\
53 \\
39 \\
45\end{array}$ & $\begin{array}{r}68.6 \\
66.3 \\
57.0 \\
121.0 \\
61.5 \\
52.9 \\
60.4 \\
61.9 \\
75.0 \\
57.2 \\
63.5 \\
58.4 \\
62.4\end{array}$ & $\begin{array}{r}5 \\
6 \\
5 \\
3 \\
15 \\
6 \\
2 \\
3 \\
6 \\
3 \\
11 \\
6 \\
10\end{array}$ & $\begin{array}{r}2 \\
13 \\
16 \\
17 \\
18 \\
20 \\
21 \\
26 \\
26 \\
27 \\
42 \\
52 \\
64\end{array}$ & $\begin{array}{r}9.6 \\
13.1 \\
13.7 \\
5.7 \\
14.1 \\
8.2 \\
13.3 \\
8.9 \\
6.8 \\
9.8 \\
13.5 \\
12.0 \\
16.4\end{array}$ \\
\hline Patchy cell necrosis & $\begin{array}{l}14 \\
21 \\
23\end{array}$ & $\begin{array}{l}50 \\
42 \\
59\end{array}$ & $\begin{array}{l}59 \cdot 4 \\
58 \cdot 6 \\
60 \cdot 4\end{array}$ & $\begin{array}{r}4 \\
15 \\
19\end{array}$ & $\begin{array}{c}32 \\
48 \\
50\end{array}$ & $\begin{array}{c}13 \cdot 3 \\
12 \cdot 0 \\
5 \cdot 8\end{array}$ \\
\hline
\end{tabular}

${ }^{2}$ Denotes portal fibrosis

TABLE III

BROMSULPHTHALEIN METABOLISM IN 27 ALCOHOLIC MEN RELATED TO PERIOD OF ABSTINENCE BEFORE STUDY

\begin{tabular}{|c|c|c|c|}
\hline $\begin{array}{l}\text { Time Abstinent } \\
\text { Before Test } \\
\text { (days) }\end{array}$ & $\begin{array}{l}\text { Number } \\
\text { of } \\
\text { Subjects }\end{array}$ & $\begin{array}{l}S_{B S P} \\
(\mathrm{mg} \text { per } \mathrm{mg} \text { per } 100 \mathrm{ml})\end{array}$ & $\begin{array}{l}\text { TmBSP } \\
(\text { mg per min })\end{array}$ \\
\hline $\begin{array}{l}7 \text { or less } \\
(4 \cdot 5 \pm 1 \cdot 7)\end{array}$ & 15 & $23 \cdot 3 \pm 12 \cdot 7$ & $10 \cdot 3 \pm 2 \cdot 8$ \\
\hline $\begin{array}{l}8-21 \\
(11 \cdot 7 \pm 3 \cdot 4) \\
P \text { value }\end{array}$ & 12 & $\begin{array}{l}45.3 \pm 14.8 \\
<0.001\end{array}$ & $\begin{array}{l}12.4 \pm 2.9 \\
\text { Not significant }\end{array}$ \\
\hline
\end{tabular}

their second or third week of abstinence were normal (Table III, Fig. 1).

In the five patients who were studied again after intervals of abstinence ranging from nine to 150 days, the initially abnormal $\mathrm{S}_{\mathrm{BSP}}$ values had all returned to normal (Table IV).

\section{DISCUSSION}

The results of the present investigation, viewed in the light of present knowledge of BSP metabolism and alcoholic liver disease, allow certain speculations and conclusions, and suggest some further in-

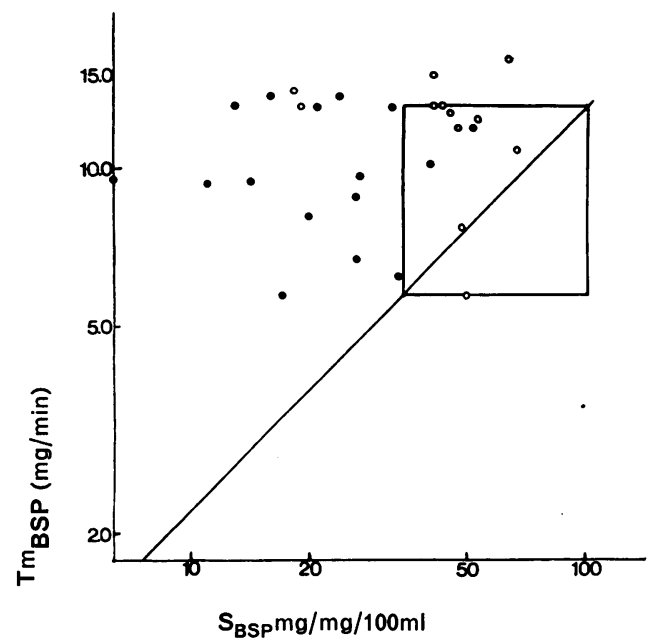

FIG.1. Bromsulphthalein storage capacity $\left(S_{\mathrm{BSP}}\right)$ and transfer maximum (Tm $\left.m_{\mathrm{BSP}}\right)$ in 27 alcoholic patients. The rectangle encloses the area of the normal mean $\pm 2 S D$ for Tm $m_{\mathrm{BSP}}$ and $S_{\mathrm{BSP}}$. All values are plotted logarithmically. The solid line marks out equal percentile changes in $T m_{\mathrm{BSP}}$ and $S_{\mathrm{BSP}}$ : where $S_{\mathrm{BSP}}$ is reduced to a greater extent than $T m_{\mathrm{BSP}}$ the result lies above the line, and where Tm $m_{\mathrm{BSP}}$ is affected more severely it lies below (after Preisig et al, 1966). $\bullet=$ tested less than one week, $\bigcirc=$ tested more than one week, after alcohol withdrawal. 
TABLE IV

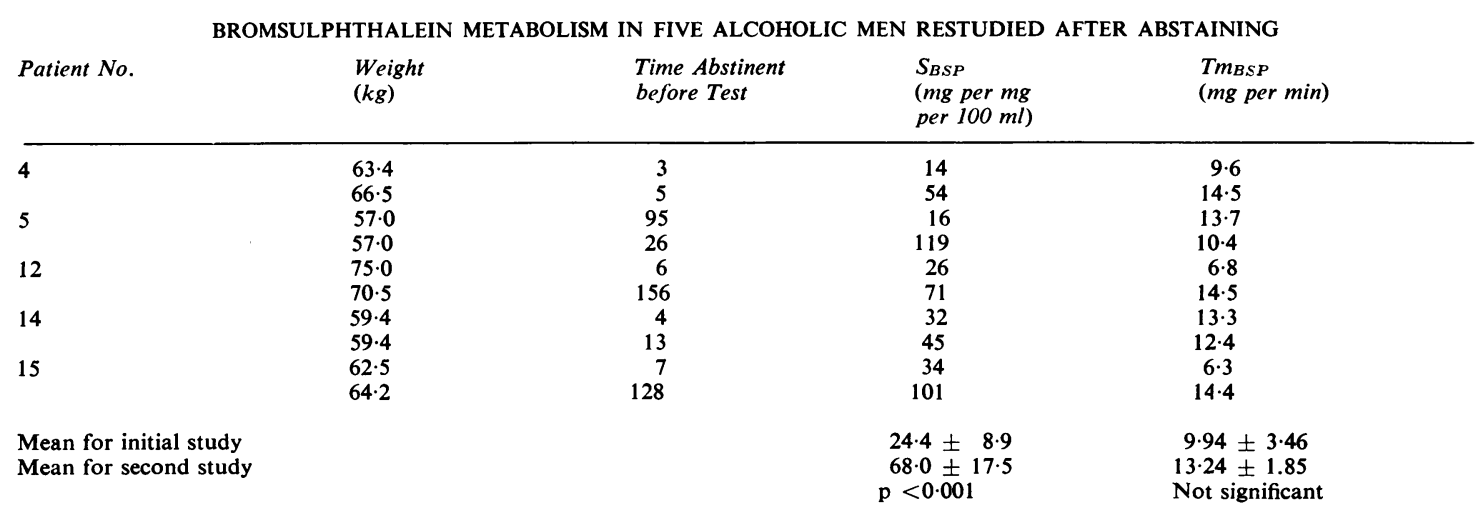

vestigations. Following its intravenous injection BSP is carried as an albumin complex in the plasma from which it is rapidly extracted and taken up by the hepatic parenchymal cells. Its removal from the plasma by the liver consists of two processes, uptake and storage in the liver which is proportional to the plasma concentration of the dye, and biliary excretion which has a maximal transport rate (Wheeler et al, 1960). During its passage from plasma to bile, BSP is enzymically conjugated with glutathione (Javitt, Wheeler, Baker, Ramos, and Bradley, 1960; Combes and Stakelum, 1961), but it is not known whether it is stored in the liver in the conjugated or unconjugated form. Baker and Bradley (1966) postulate that the dye may be conjugated at the hepatocyte border during its extraction from the BSP-albumin complex, so that it would be stored in conjugated form. However, Combes (1962) found that $\mathrm{S}_{\mathrm{BSP}}$ was independent of conjugating ability, suggesting that it is stored in the unconjugated state.

Previous studies of BSP metabolism (Wheeler et al, 1960; Preisig et al, 1966) have shown that where there is loss of total functioning liver cell mass, as in cirrhosis and viral hepatitis, $\mathbf{S}_{\mathrm{BSP}}$ and $\mathrm{Tm}_{\mathrm{BSP}}$ are proportionately reduced, The only conditions in which a selective reduction of $\mathrm{S}_{\mathrm{BSP}}$ has previously been reported are extrahepatic portal hypertension, due to portal vein thrombosis (Thompson, Williams, and Sherlock, 1964) and advanced age (Thompson and Williams, 1965). In the present study, SBSP was similarly reduced in 13 out of 15 patients who had been drinking within a week of investigation. The abnormality was unrelated to changes visible with the light microscope, and it was rapidly reversible with time. These results suggest that the reduction in $S_{\text {BSP }}$ does not indicate any loss of overall cell function, but rather a selective cellular change. This could be caused by some intracellular injury too subtle to be recognized by the light microscope, or by some disturbance of the splanchnic circulation. Early structural changes in the liver cell, which have been identified by electron microscopy in acute alcoholic liver disease, include damage to the mitochondria and endoplasmic reticulum (Kiessling, Pilstrom, Strandberg, and Lindgren, 1965; Porta, Bergmen, and Stein, 1965). Rubin and Lieber (1967) have demonstrated that such changes can be induced by excessive alcohol ingestion combined with an otherwise normal diet, that they occur very early in alcoholic liver disease and precede fatty infiltration observable under the light microscope. Decreased oxidative powers of the mitochondria or disturbed enzyme activity in the endoplasmic reticulum of damaged cells could explain the reduced $S_{\mathrm{BSP}}$ observed in the alcoholic patients reported here. A selective disturbance of $S_{B S P}$ might thus be the earliest biochemical indicator of liver damage, TmBSP falling commensurately only when severe cell damage or cell necrosis ensued.

Alternatively, selective abnormalities of $S_{\mathrm{BSP}}$ could result from decreased delivery of portal blood to the liver cells. Hepatic perfusion is abnormal in extrahepatic portal hypertension and is also possibly reduced with advancing age. In both of these conditions a selective reduction of $\mathrm{S}_{\mathrm{BSP}}$ has been found (Thompson et al, 1964; Thompson and Williams, 1965). Leevy, Zinke, Baber, and Chey (1958) and Chiandussi, Greco, Indovina, Cesano, Vaccarino, and Muratori (1963) have demonstrated reversible portal hypertension in patients with alcoholic fatty livers. Therefore it is possible that in acute alcoholic liver disease disturbances to vascular perfusion may impede the delivery of either dye or oxygen, or both, to the hepatocytes, and so lead to the reduction in $S_{\text {BSP reported here. }}$

The change in BSP metabolism described in these patients may be a specific effect of prolonged alcoholic excess, or it may be caused by other 
factors such as vitamin or protein deficiencies, congeners or excessive iron in certain alcoholic beverages, coexistent viral hepatitis, or some combination of these. Some workers have thought that alcoholic fatty liver is but a manifestation of the alcoholic's poor food intake (Best, Hartroft, Lucas, and Ridout, 1949). Traditionally, certain alcoholic beverages have been thought to be more toxic than others. Recently, however, Rubin and Lieber (1967) have shown that ethyl alcohol itself can cause many of the morphological changes seen in acute alcoholic liver disease. Likewise, it seems possible that the functional abnormality found in the alcoholic patients studied here is predominantly, if not exclusively, due to alcohol excess. The disturbance of BSP metabolism was not related to any coexisting clinical deficiency state such as peripheral neuropathy, the type of beverage drunk, or the pattern of drinking. Well nourished, continuous heavy drinkers were affected as severely as 'spree' drinkers who neglected to eat during drinking bouts, and beer drinkers as badly as those who drank wine or spirits. The crucial factor for the disturbance in BSP metabolism appeared to be the period of withdrawal of ethyl alcohol.

Two possible extensions of the present study are apparent. First, the direct effect of ethyl alcohol on the liver could be assessed by a controlled investigation similar to that of Rubin and Lieber (1967). Bromsulphthalein metabolism, hepatic ultrastructure, and possibly splanchnic haemodynamics could be studied simultaneously while patients received large amounts of alcohol together with an otherwise normal diet. Secondly, by measuring conjugated and unconjugated BSP circulating in the plasma of alcoholic patients infused with BSP, it might be possible to determine whether the dye is normally stored in the liver in the conjugated or unconjugated form. Such studies are warranted because of the frequency and potential morbidity of liver damage in chronic alcoholism. They may also elucidate some of the pathways of normal hepatic metabolism.

\section{SUMMARY}

The relative storage capacity of the liver $\left(\mathbf{S}_{\mathrm{BSP}}\right)$ and the biliary transport maximum (TmBSP) for bromsulphthalein were measured by a constant infusion method in 27 male patients who had recently been drinking excessive amounts of alcohol. Other biochemical tests of liver function and needle biopsies of the liver were also performed. Patients with histological evidence of cirrhosis were excluded.

In 15 of the 27 men a selective reduction of $S_{\text {BSP }}$ was found while $\operatorname{Tm}_{\mathrm{BSP}}$ remained within normal limits. This reduction was not related to any hepatic histological changes observable by light microscopy. It was more severe in patients tested within a week of alcohol withdrawal than in those tested later. Five patients in whom $S_{\text {BSP }}$ was initially reduced had normal values when studied again after intervals of abstinence ranging from nine to 150 days.

We are grateful to Dr Sheila Clifton for her help and to Miss Patricia Cockburn, Miss Helen Malone, and Miss Wilma Huygens for technical assistance. One of us (P.W.) was supported by a fellowship from Roche Products Pty Ltd during part of this work.

\section{REFERENCES}

Baker, K. J., and Bradley, S. E. (1966). Binding of sulfobromophthalein (BSP) sodium by plasma albumin: its role in hepatic BSP extraction. $J$. clin. Invest., 45, 281-287.

Ballard, H., Bernstein, M., and Farrar, J. T. (1961). Fatty liver presenting as obstructive jaundice. Amer. J. Med., 30, 196-201.

Best, C. H., Hartroft, W. S., Lucas, C. C., and Ridout, J. H. (1949). Alcohol and sugar. Liver damage produced by feeding alcohol or sugar and its prevention by choline. Brit. med. J., 2, 10011006.

Chiandussi, L., Greco, F., Indovina, D., Cesano, L., Vaccarino, A., and Muratori, F. (1963). Hepatic steatosis and portal hypertension with presinusoidal obstruction. Gastroenterology, 44, 532-535.

Combes, B. (1962). The importance of conjugation with glutathione on sulfobromophthalein (B.S.P.) transport from blood to bile. J. clin. Invest. (Abstr.), 41, 1351.

sulfobromophthalein sodium with glutathione. Ibid., 40, 981-988.

Green, J., Mistilis, S., and Schiff, L. (1963). Acute alcoholic hepatitis: a clinical study of fifty cases. Arch. intern. Med., 112, 67-78.

Green, J. R. (1965). Subclinical acute liver disease of the alcoholic. Aust. Ann. Med., 14, 111-124.

Javitt, N. B., Wheeler, H. O., Baker, K. J., Ramos, O. L., and Bradley, S. E. (1960). The intrahepatic conjugation of sulphobromophthalein and glutathione in the dog. J. clin. Invest., 39, 15701577.

Kiessling, K.-H., Pilstrom, L., Strandberg, B., and Lindgren, L. (1965). Ethanol and the human liver. Correlation between mitochondrial size and degree of ethanol abuse. Acta med. scand., 178, 533-535.

Leevy, C. M. (1962). Fatty liver: a study of 270 patients with biopsy proven fatty liver and a review of the literature. Medicine (Baltimore), 41, 249-276.

_- Zinke, M., Baber, J., and Chey, W. Y. (1958). Observations on the effect of medical therapy on portal hypertension in hepatic cirrhosis. Ann. intern. Med., 49, 837-851.

Porta, E. A., Bergman, B. J., and Stein, A. A. (1965). Acute alcoholic hepatitis. Amer. J. Path., 46, 657-689.

Preisig, R., Williams, R., Sweeting, J., and Bradley, S. E. (1966). Changes in sulfobromophthalein transport and storage by the liver during viral hepatitis in man. Amer. J. Med., 40, 170-183.

Rubin, E., and Lieber, C. S. (1967). Early fine structural changes in the human liver induced by alcohol. Gastroenterology, 52, 1-13.

Sataline, L. R., and Matre, W. J. (1963). Significance of hyperphosphatasemia in alcoholics with liver disease. An analysis of fifty-eight cases, with histologic diagnoses. Amer. J. Med., 35, 323-342.

Seligson, D., Marino, J., and Dodson, E. (1957). Determination of sulfobromophthalein in serum. Clin. Chem., 3, 638-645.

Thompson, E. N., and Williams, R. (1965). Effect of age on liver function with particular reference to bromsulphalein excretion. Gut, 6, 266-269.

- - - and Sherlock, S. (1964). Liver function in extrahepatic portal hypertension. Lancet, 2, $1352-1356$.

Wheeler, H. O., Meltzer, J. I., and Bradley, S. E. (1960). Biliary transport and hepatic storage of sulphobromophthalein sodium in the unanesthetised dog, in normal man, and in patients with hepatic disease. J. clin. Invest., 39, 1131-1144. 